\title{
Significance of Laurén's Classification in Chemotherapy of Gastric Carcinoma
}

\author{
Goro Kakizaki, Yoshiyuki Fujiwara, Eitchi Kato, Takayuki \\ SaIto, Toyokichi Maeta, Takuzo Ishidate and Iwao Ono* \\ Department of Surgery, and Department of Pathology,* Akita \\ University School of Medicine, Akita
}

Kakizaki, G., Fujiwara, Y., Kato, E., Saito, T., Mafeta, T., Ishidate, T. and ONo, I. Significance of Laurén's Classification in Chemotherapy of Gastric Carcinoma. Tohoku J. exp. Med., 1976, 119 (1), 41-49 The effects of anticancer agents were studied on the basis of survival rates following surgery for gastric carcinomas in different histologic types of Laurén's classification. It was revealed that Laurén's classification would provide an index to the use of anticancer agents to a certain extent. Anticancer agents were effective against diffuse gastric carcinoma, and should therefore be intensively used for treatment of this malignancy. For female patients with diffuse gastric carcinoma, careful selection of adequate anticancer agents is highly necessary. Anticancer agents were less effective against intestinal-type carcinoma, and it would therefore be necessary to use anticancer agents on the aged male patient with this malignancy by taking his age and side effects of the agents into consideration. - - gastric carcinoma; anticancer agents

In a recent study of the effects of chemotherapy of gastric carcinoma, the postoperative survival rate in operated patients was analyzed from various aspects. The present paper deals with the analysis of efficacy of chemotherapy in different efficacy types of gastric carcinoma of Laurén's classification (D.I.O. classification).

\section{Sưjects and Methods}

As presented in Table 1, the subjects consisted of a total of 823 patients who were operated on for gastric carcinoma at The Akita Prefecture Central Hospital and The Akita University Hospital during about 10 years' period from January, 1965, through June, 1974. A survey was made by the questionnaire system on 801 patients, excluding 22 who died during hospitalization. Answers covering 580 of them were received, the answering rate being about $72 \%$. Of the 580 patients, $357(62 \%)$ had died after discharge, and 340

TABLE 1. The patients examined.

\begin{tabular}{cccccc}
\hline \multirow{2}{*}{$\begin{array}{c}\text { Numbers of } \\
\text { total cases }\end{array}$} & $\begin{array}{c}\text { Death during } \\
\text { hospitalization }\end{array}$ & \multicolumn{3}{c}{ Questionnaires } & Death after \\
hospital \\
\hline 823
\end{tabular}

Received for publication, November $29,1975$. 
of them, equivalent to $59 \%$ of the patients discharged, had died of cancer. Of these 580 patients, 130 were excluded because they had been operated on for early gastric carcinoma and the D.I.O. classification could not be determined. In consequence the remaining 450 patients were analyzed for the effect of anticancer agents on the survival rate from the point of view of D.I.O. classification. The cases of unknown status were excluded.

\section{D.I.O. Classification}

D.I.O. classification is a histologic classification of gastric carcinomas proposed by Järvi and Laurén (1951) and by Laurén (1965), which classifies gastric carcinomas into two major types, i.e., intestinal-type carcinoma and diffuse gastric carcinoma. This classification has recently been used in the epidemiological analysis as representing different biological behaviors of gastric carcinomas. Table 2 summarizes the histologic features of these two types of malignant tumors in the sequence as cited by Laurén (1965). As shown in Fig. 1, the intestinal-type carcinoma is a differentiated adenocarcinoma presenting apparent glandular structure and also characteristic histologic picture of the intestinal epithelium with a brush border on the surface of the lumen. On the other hand, the diffuse gastric

TABLE 2. Comparison of two main gastric histological types by Laurén

\begin{tabular}{|c|c|c|}
\hline & $\begin{array}{l}\text { Intestinal-type } \\
\text { carcinoma }\end{array}$ & Diffuse carcinoma \\
\hline $\begin{array}{l}\text { Glandular lumina } \\
\text { Cell polarization } \\
\text { Apical surface of cell } \\
\text { Brush border }\end{array}$ & $\begin{array}{l}\text { Present and large } \\
\text { Well polarized } \\
\text { Continued unbroken } \\
\text { Well developed }\end{array}$ & $\begin{array}{l}\text { Absent or small } \\
\text { Unpolarized } \\
\text { Wavy form } \\
\text { Uneven. Bristles are } \\
\text { sparse }\end{array}$ \\
\hline $\begin{array}{ll}\text { Cytoplasm Size } \\
\text { Shape }\end{array}$ & $\begin{array}{l}\text { Large } \\
\text { Variable }\end{array}$ & $\begin{array}{l}\text { Fragile } \\
\text { Uniform }\end{array}$ \\
\hline $\begin{array}{ll} & \text { Size } \\
\text { Nuclei } & \text { Shape } \\
& \text { Mitosis } \\
& \text { Chromatin }\end{array}$ & $\begin{array}{l}\text { Large } \\
\text { Variable } \\
\text { Often } \\
\text { Hyperchromatic }\end{array}$ & $\begin{array}{l}\text { Small } \\
\text { Regular } \\
\text { Rare } \\
\text { Pyknotic }\end{array}$ \\
\hline $\begin{array}{l}\text { Secretion in the } \\
\text { cytoplasm }\end{array}$ & $\begin{array}{l}\text { Forming a distinctly } \\
\text { defined theca }\end{array}$ & Evenly distributed \\
\hline $\begin{array}{l}\text { Extracellular secreted } \\
\text { mucus }\end{array}$ & $\begin{array}{l}\text { Located in the } \\
\text { glandular lumina }\end{array}$ & Dispersed in the stroma \\
\hline Colloid carcinoma & $11 \%$ & $21 \%$ \\
\hline Mode of growth & $\begin{array}{l}\text { The type of tumor } \\
\text { tissue varies in the } \\
\text { different parts }\end{array}$ & Not differ \\
\hline Spreading & Clearly defined area & Not defined \\
\hline $\begin{array}{l}\text { Inflammatory cell } \\
\text { infiltration }\end{array}$ & Profuse & Slight \\
\hline Enterochromaffin cells & Less frequent & More frequent \\
\hline
\end{tabular}




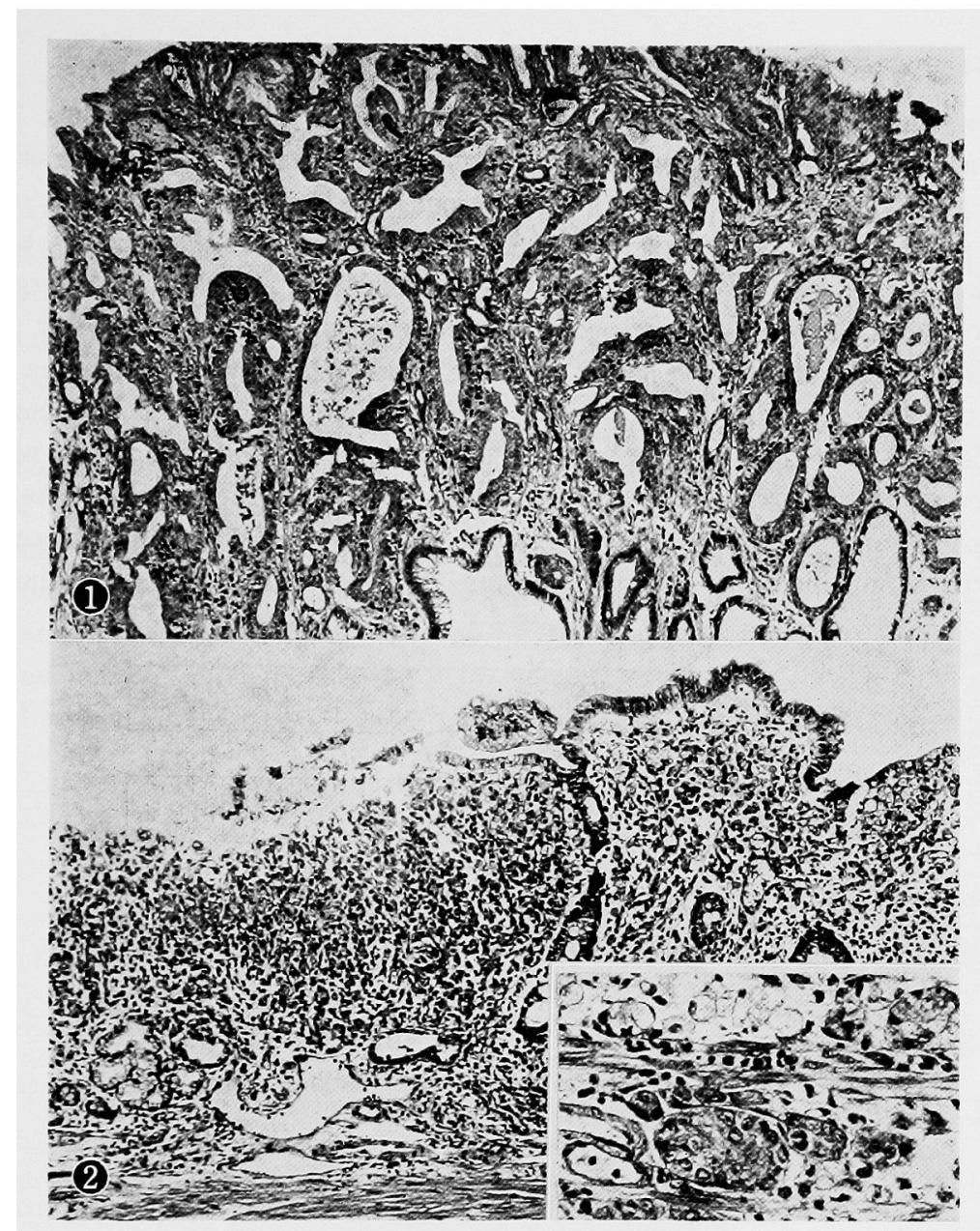

Fig. 1. Histologic picture of intestinal type carcinoma. This case is the protruded type of early gastric carcinoma, showing typical histologic pattern of this type with distinct glandular lumen and differentiation to the intestinal epithelium. In lower corner, non-neoplastic intestinal glands are seen. (H.E. stain)

Fig. 2. Histologic picture of diffuse gastric carcinoma. This case is the depressed type of early gastric carcinoma, showing typical histologic pattern of this type such as diffuse infiltration in the mucosa. In right lower corner, signet-ring cells and carcinomas without glandular lumen are seen. (H.E. stain)

carcinoma, as shown in Fig. 2, does not present any definite glandular structure, but infiltrates diffusely accompanied by occasional signet-ring cells. It is well known that scirrhous carcinoma is the representative of gastric carcinomas presenting such a histologic picture. There were, in reality, a few cases which could not be classified into either of these two types, and they were designated as "other". This classification is often called D.I.O. in abbreviation, which stands for the initial letters of diffuse, intestinal and other. 
Relations of D.I.O. classification to sex and age

The relations of D.I.O. classification to age and sex are shown in Figs. 3 and 4. It is common that the intestinal-type carcinoma (hereinafter referred to as I type) is more frequent than the diffuse gastric carcinoma ( $D$ type) in the male, while D type is almost as frequent as I type in the female (Fig. 3). Although it has been shown in an epidemiological study that I type carcinoma accounts for a larger part of gastric carcinomas in the district where the incidence of cancer is high ( $\mathrm{Mun}$ oz et al. 1968), this finding is consistent with the finding that I type carcinoma is more frequent in the male than in the female. Also as given in Fig. 4, D type carcinoma accounted for almost all cases of gastric carcinoma in the low age group, while the incidence of I type carcinoma tended to be high over the fifties. The higher incidence of cancer in the male may be attributed mainly to the frequent occurrence of I type carcinoma in the high age group. The above findings are similar to

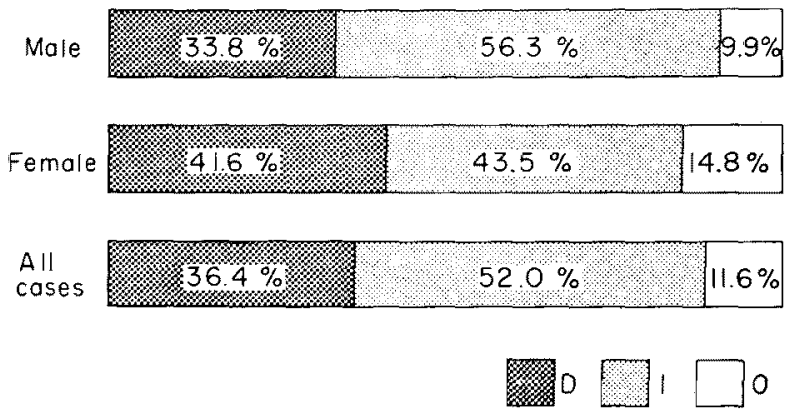

Fig. 3. Relation of D.I.O. classification to sex.

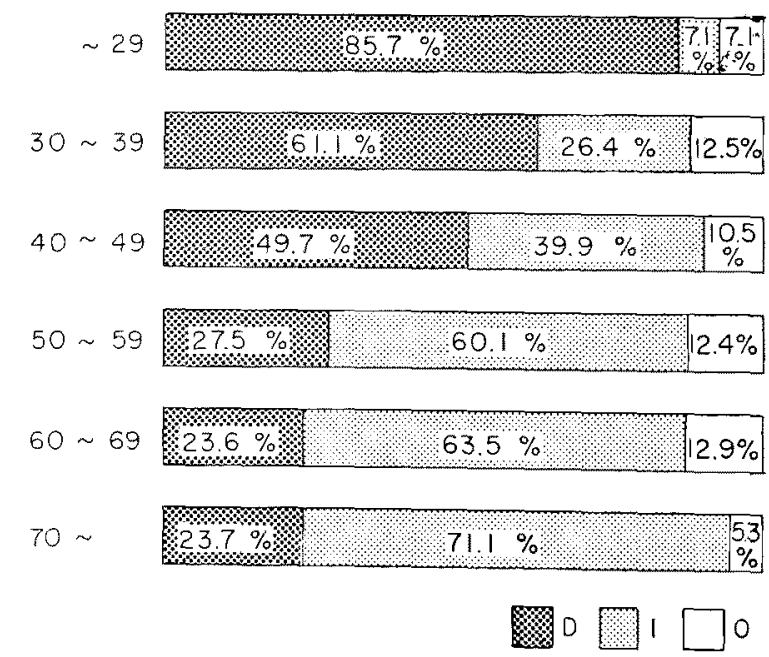

Fig. 4. Relation of D.I.O. classification to age. 
those by Laurén (1965), who studied the D.I.O. classification, sex and age in 1,344 patients operated on for gastric carcinomas.

\section{D.I.O. classification and clinico-pathologic features}

Biological variations in the histologic types of cancer as described above were studied from the clinico-pathologic point of view, and the findings are given in Table 3. The majority of cases of D type carcinoma were grossly of depressed and ulcerative type, and especially in advanced cancer, this type of carcinoma was mostly classified to Borrmann's type IV ro III, while many cases of I type carcinoma were of elevated or protruded type, and many of them were type I or II by Bormann including some cases of advanced type III. Generally, the behavior of carcinoma extension also varied in these two types; that is, $D$ type carcinoma is often associated with peritonitis carcinomatosa, while I type carcinoma with nodular metastasis to the liver. It is also said that as described in the foregoing, D type carcinoma is frequently encountered in the younger age group and women, and I type carcinoma in the older age group and men (Laurén 1965; Muñoz et al. 1968).

TABLE 3. Clinico-pathologic difference between intestinal-type and diffuse gastric carcinoma

\begin{tabular}{|c|c|c|}
\hline & Intestinal-type carcinoma & Diffuse carcinoma \\
\hline Origin of carcinoma & $\begin{array}{l}\text { Metaplastic intestinal epi- } \\
\text { thelium in gastric mucosa }\end{array}$ & $\begin{array}{l}\text { Gastric proper epithelium, } \\
\text { suspected }\end{array}$ \\
\hline \multirow{2}{*}{$\begin{array}{l}\text { Gross } \\
\text { finding } \\
\\
\begin{array}{l}\text { Advanced } \\
\text { carcinoma }\end{array}\end{array}$} & Mostly elevated type & Mostly depressed type \\
\hline & Borrmann's type I, II, III & Borrmann's type IV, III \\
\hline $\begin{array}{l}\text { The mode of extension } \\
\text { in gastric wall }\end{array}$ & Localized & Diffuse \\
\hline Peritoneal dissemination & Not frequent & Frequent \\
\hline Metastasis to the liver & $\begin{array}{l}\text { Hematogenous nodular me- } \\
\text { tastasis through portal vein }\end{array}$ & $\begin{array}{l}\text { Lymphogenous diffuse me- } \\
\text { tastasis }\end{array}$ \\
\hline Metastasis to the lung & $\begin{array}{l}\text { Hematogenous nodular me. } \\
\text { tastasis }\end{array}$ & $\begin{array}{l}\text { Lymphogenous metastasis } \\
\text { through peribronchial lym- } \\
\text { phatic canal }\end{array}$ \\
\hline Age and sex & $\begin{array}{l}\text { Frequent in older age group } \\
\text { and male }\end{array}$ & $\begin{array}{l}\text { Frequent in younger age } \\
\text { group and female }\end{array}$ \\
\hline
\end{tabular}

Effects of Anticancer Agents in Difeerent Types of D.I.O. Classification

Survival rates in all cases

As shown in Fig. 5, the survival rate in I type cases was apparently higher 
than that in $D$ type cases. The results of analysis of the survival rates classed by sex are given in Fig. 6. The survival rate in men with I type carcinoma tended to be lower than that in the female counterpart. It may be considered responsible for this finding that I type carcinoma is more frequent in men, and that the aged patients account for the majority of them. The survival rate in women with $D$ type carcinoma tended to be lower than that in the male counterpart, and this tendency may be attributable to the fact that women accounted for a large part of patients with $\mathrm{D}$ type carcinoma which is more malignant in nature.

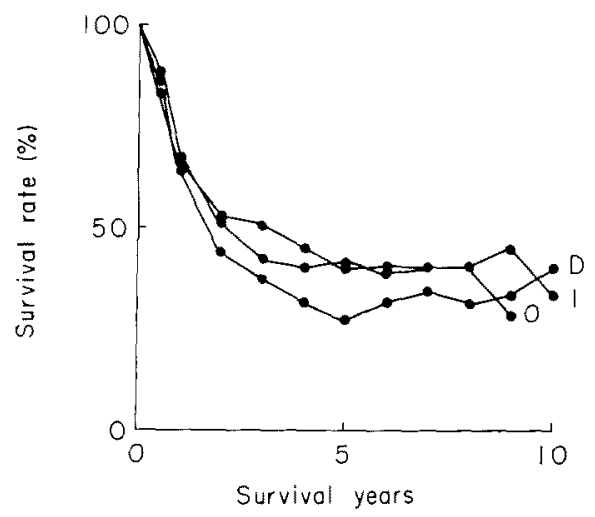

Fig. 5. Survival rate in all cases.
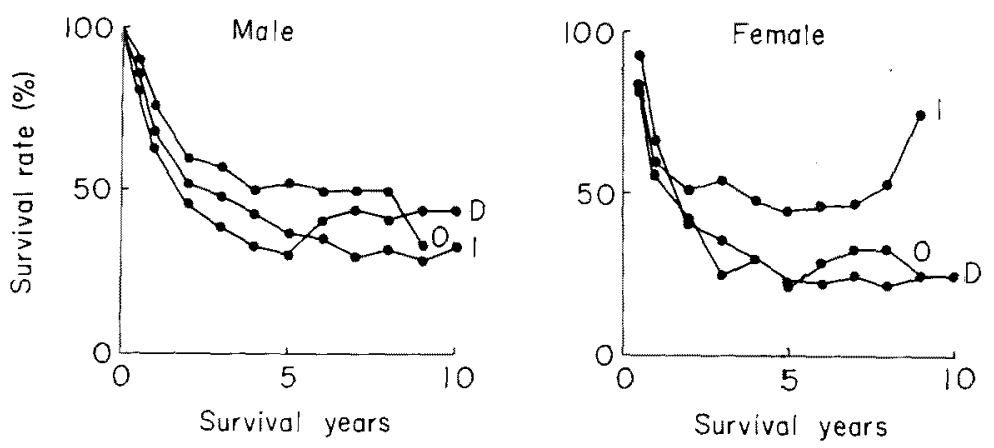

Fig. 6. Survival rate classed by sex.

Comparison in the survival rate between cases treated with anticancer agent and
untreated cases

As shown in Fig. 7, long-term survival was more frequent in $D$ type cases treated with anticancer agents than in the cases not treated with the agents, while the five-year survival rate was higher in the untreated cases. In view of this result, it appears that there are cases of $D$ type which are responsive to anticancer agents and those which are not responsive. 



Fig. 7. Survival rate in cases treated with anticancer agent and that in cases untreated.

Effects of anticancer agents, classed by sex

As shown in Fig. 8, the survival rate in male patients treated with anticancer agents for $\mathrm{D}$ type carcinoma was high, and there were many long-term survivors in them. In view of this finding, anticancer agents may be effective against D type carcinoma. On the other hand, the survival rate in patients treated with anticancer agents for I type carcinoma was low, and as described above, this low survival rate may be attributed to the fact that male patients with I type carcinoma included many aged patients. For this reason, it appears necessary to use anticancer agents on the male patient with I type carcinoma by taking his age and side effects of the agents into consideration.
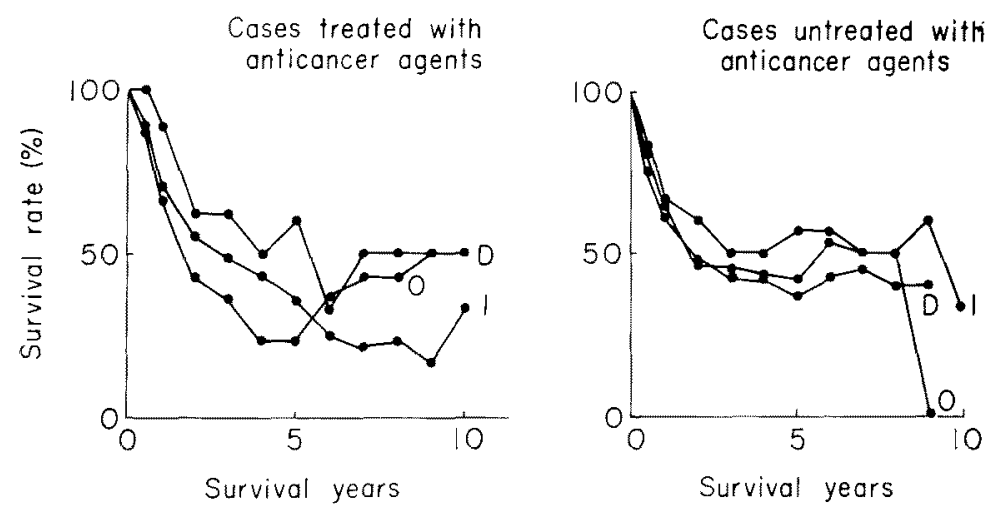

Fig. 8. Effect of anticancer agent in male.

On the other hand, as shown in Fig. 9, the survival rate in female patients treated with anticancer agents for I type carcinoma was almost comparable to that in the untreated counterpart. This finding seems to be attributable to the effect that, unlike male patients with I type carcinoma, female patients with this 

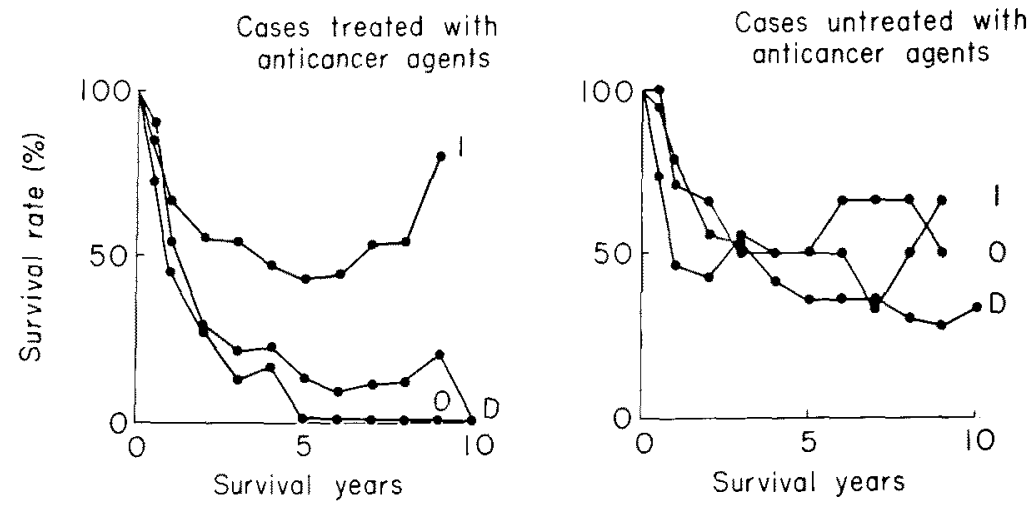

Fig. 9. Effect of anticancer agent in female.

malignancy consisted of a smaller number of aged patients, and the finding that the survival rates in both groups of female patients were almost comparable to each other may indicate that anticancer agents are not so influential on the malignancy of this type. The survival rate in patients with $D$ type carcinoma tended to be lower in patients treated with anticancer agents; however, the fact that such a result was attained despite that the patients with $\mathbf{D}$ type carcinoma consisted of many young women may indicate either that anticancer agents exert more serious side effects on women or that it is necessary to use adequate varieties of anticancer agents in the treatment of $\mathrm{D}$ type carcinoma.

\section{Comparison in the effects of anticancer agents between both sexes}

The analysis of the survival rate in the patients treated with anticancer agents revealed that, as shown in Fig. 10, the survival rate in male patients with D type carcinoma was higher than that in the female counterpart and that in male patients with I type carcinoma was extremely low. On the other hand, the analysis of the rate in the untreated patients revealed that, as shown in Fig. 11, there was virtually no difference in survival rate either between male and female
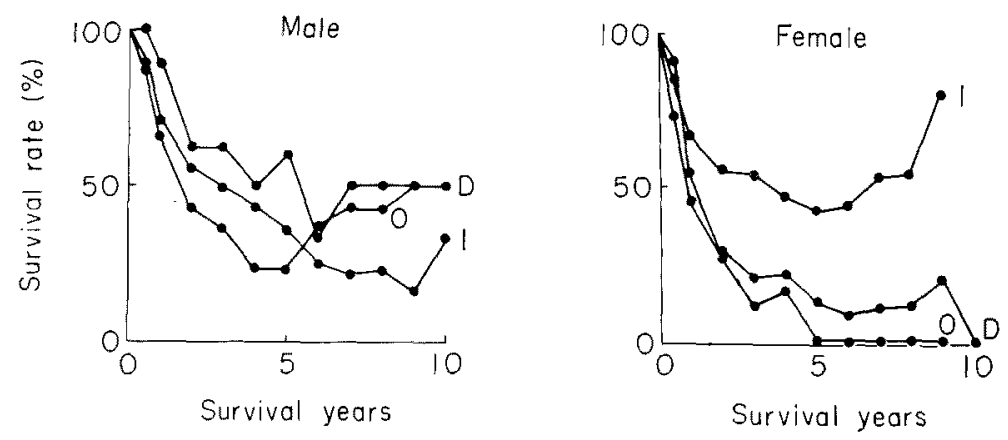

Fig. 10. Survival rate in cases treated with anticancer agent classed by sex. 

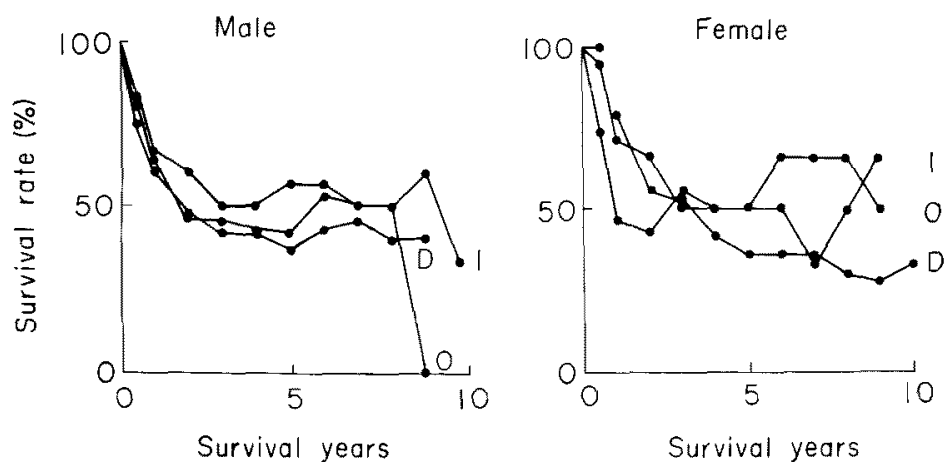

Fig. 11. Survival rate in cases untreated with anticancer agent classed by sex.

patients with $D$ type carcinoma or between those with I type malignancy.

The findings presented above implies that anticancer agents should be intensively used in the treatment of $\mathrm{D}$ type gastric carcinoma, while it is necessary to select carefully adequate anticancer agents for women. Anticancer agents are less effective against I type gastric carcinoma, and it is necessary to consider the age of patient and side effects of anticancer agents when the aged male patient with I type gastric carcinoma is treated with the agents.

\section{References}

1) Järvi, O. \& Laurén, P. (1951) On the role of heterotopias of the intestinal epithelium in the pathogenesis of gastrie cancer. Acta path. microbiol. seand., 29, 26-44.

2) Laurén, P. (1965) The two histological main types of gastric carcinoma: Diffuse and so-called intestinal-type carcinoma. An attempt at a histo-clinical classification. Acta path. microbiol. scand., 64, 31-49.

3) Muñoz, N., Correa, P., Cuello, C. \& Duque, E. (1968) Histologic types of gastric carcinoma in high- and low-risk areas. Int. J. Cancer, 3, 809-818. 